Anal ysi s perfor nance of triangle microstrip ant enna for basi c construction of ci rcul arly pol ar i zed- synt het i c aperture radar appl i cat i on

\begin{tabular}{|l|l|}
\hline 著者 & Purnono Munammad Fauzan Edy, Ki t agawa Aki o \\
\hline 著者別表示 & 北川 章夫 \\
\hline $\begin{array}{l}\text { j our nal or } \\
\text { publ i cat i on ti t l e }\end{array}$ & Jurnal Teknol ogi \\
\hline vol une & 80 \\
\hline number & 2 \\
\hline page r ange & $93-104$ \\
\hline year & 2018 -03 \\
\hline URL & ht t p: //doi . or g/10. 24517/00050522 \\
\hline
\end{tabular}




\section{Analysis Performance of TRIANgle Microstrip ANTENNA FOR BASIC CONSTRUCTION OF CIRCULARLY POLARIZED-SYNTHETIC APERTURE RADAR APPLICATION}

\author{
Muhammad Fauzan Edy Purnomoa,b*, Akio Kitagawa
}

aElectrical Engineering and Computer Science, Graduate School of Natural Science and Technology, Kanazawa University, Kakuma-machi, Kanazawa, Ishikawa 920-1192, Japan bElectrical Engineering Department, Faculty of Engineering, Brawijaya University, Malang, East Java, 65145, Indonesia
Article history

Received

1 June 2017

Received in revised form 25 September 2017

Accepted

10 January 2018

*Corresponding author

purnomo@merl.jp mfauzanep@ub.ac.id

\section{Graphical abstract}

Determine the SAR, CP-SAR, and geostationary satellite with variety of platforms, which can generate processed data with high quality resolution image.

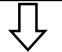

Consideration of generating data need transmitter and receiver antenna which is compact, small, and simple configuration i.e. model $\mathrm{c} 1, \mathrm{c} 2$, c3, c3s and equilateral triangle antenna using MoM.

\section{凤}

The performance characteristic of those antennas are CP and appropriate with the desired technical specification. The whole result of performance characteristic of c3s antenna is the smallest antenna size, although the axial ratio bandwidth decreases compared with the other. But, the good result for complete simulation and measurement of the equilateral triangle antenna using microstrip-line feed are similar values of gain and axial ratio at $2.5 \mathrm{GHz}$ with the other antennas.

\begin{abstract}
The development of radar technology, Synthetic Aperture Radar (SAR), Circularly Polarized-Synthetic Aperture Radar (CP-SAR) and geostationary satellite, are demanding needs of communication facilities and infrastructures that have variety platforms, which can generate processed data with high resolution and better image quality for all types of explored terrain. Owing to the antenna embedded on the body of geostationary satellite, its shape should be compact, small, and simple configuration, i.e. the equilateral triangle with and without truncated-tip c1,c2, c3, and c3s antennas using probe and microstrip-line feed with low-power at S-band (2.5 GHz-2.9 GHz). The Method of Moments $(\mathrm{MOM})$ is chosen in the numerical analysis for fast calculation. The performance results for c2 and c3 antennas are almost same, for instance the values of gain and axial ratio (Ar) for each antenna are consecutive of $6.8 \mathrm{dBic}$ and $0.42 \mathrm{~dB}$. Moreover, the performance results for $\mathrm{cl}, \mathrm{c} 3$, and $\mathrm{c} 3 \mathrm{~s}$ antennas at the each resonant frequency are relatively different, as follows: $\mathrm{Cl}$ antenna operates at the frequency $2.76 \mathrm{GHz}$, gain $\mathrm{RHCP}=6.66 \mathrm{dBic}, \mathrm{Ar}=$ $2.91 \mathrm{~dB}$, the operation frequency of $\mathrm{c} 3$ antenna is $2.9 \mathrm{GHz}$, gain $\mathrm{LHCP}=6.98 \mathrm{dBic}, \mathrm{Ar}=3.02$ $\mathrm{dB}$, and for $\mathrm{c} 3 \mathrm{~s}$ antenna has the operation frequency of $2.5 \mathrm{GHz}$, gain $\mathrm{LHCP}=6.08 \mathrm{dBic}, \mathrm{Ar}$ $=1.75 \mathrm{~dB}$. The results for both simulation and measurement of equilateral triangle antenna, especially for $\mathrm{Ar}$ bandwidth below $3-\mathrm{dB}$ are about $0.02 \mathrm{GHz}$ and $0.015 \mathrm{GHz}$, respectively. Furthermore, the results of the $3 \mathrm{~dB}-\mathrm{Ar}$ beamwidth for simulation and measurement in elevation plane are consecutively about $120^{\circ}$ and $80^{\circ}$.
\end{abstract}

Keywords: CP-SAR, geostationary satellite, equilateral triangle, truncated-tip, MoM

\begin{abstract}
Abstrak
Perkembangan teknologi radar, SAR, CP-SAR, dan satelit geopegun, menuntut keperluan kemudahan perhubungan dan infrastruktur yang mempunyai pelbagai platform, yang boleh menjana proses data dengan resolusi tinggi dan kualiti imej yang lebih baik untuk semua jenis kawasan terokai. Kerana antena tertanam pada badan satelit geopegun, bentuknya harus padat, kecil, dan konfigurasi mudah, iaitu segi tiga sama sisi dengan $\mathrm{cl}$ dipenggal-tip, c2, c3 dan c3s, dan tanpa dipenggal-tip antena dengan siasatan dan suapan mikrostrip talian menggunakan kuasa rendah dalam $S$-band $(2.5 \mathrm{GHz}-2.9 \mathrm{GHz})$. Kaedah Moments, MOM dipilih dalam analisis berangka banyak cepat. Hasil daripada prestasi bagi antena c2 dan c3 adalah hampir sama iaitu misalnya nilai gain dan Ar untuk setiap antena kali berturut-turut $6.8 \mathrm{dBic}$ dan $0.42 \mathrm{~dB}$. Selain itu, hasil daripada prestasi untuk $\mathrm{cl}$, c3 dan c3s antena di setiap frekuensi salunan agak berbeda, seperti berikut: $\mathrm{cl}$ antena beroperasi di kekerapan $2.76 \mathrm{GHz}$, mendapat $\mathrm{RHCP}=6.66 \mathrm{dBiC}, A r=2.91 \mathrm{~dB}$, operasi frekuensi $\mathrm{C} 3$ antena adalah $2.9 \mathrm{GHz}$, mendapat $\mathrm{LHCP}=6.98 \mathrm{dBic}, \mathrm{Ar}=3.02 \mathrm{~dB}$, dan untuk antenna c3s mempunyai operasi frekuensi $2.5 \mathrm{GHz}$, mendapat $\mathrm{LHCP}=6.08 \mathrm{dBic}$, $\mathrm{Ar}$ $=1.75 \mathrm{~dB}$. Hasil daripada simulasi dan pengukuran antena segi tiga sama sisi, terutama bagi Ar jalur lebar di bawah $3 \mathrm{~dB}$ adalah masing-masing sekitar $0.02 \mathrm{GHz}$ dan $0.015 \mathrm{GHz}$.
\end{abstract}


Tambahan pula, hasil daripada $3 \mathrm{~dB}-A r$ beamwidth untuk simulasi dan pengukuran berturut-turut adalah kira-kira $120^{\circ}$ dan $80^{\circ}$.

Kata kunci: CP-SAR, satelit geopegun, segi tiga sama sisi, terpenggal-tip, MoM

\subsection{INTRODUCTION}

Microstrip antenna has several characteristics that are small shape, lightweight, relatively low manufacturing cost, and large area working frequency between 400 $\mathrm{MHz}$ to $60 \mathrm{GHz}$. Also, it can be integrated with the Microwave Integrated Circuit (MIC). Moreover, microstrip antenna is widely used in Personal Communication system (PCS), mobile satellite communication, Direct Broadcast Satellite (DBS), Wireless Local Area Networks (WLAN), and radar [1].

Synthetic Aperture Radar (SAR) in the microwave band is an active sensor that can produce highresolution image in the microwave band. The use of microwave frequency allows the penetration through clouds or forest canopy for lower frequency bands. Moreover, there are some limitations of the SAR sensor due to the phenomenon of propagation such as the geometrical variation between the radar system and the earth, the phase shift when the microwave touch the earth smoothly, and the reflective surfaces. This phenomenon causes the unwanted backscatter modulation signal and redistribution random back signal-energy, also makes the formed image seem blurring and defocusing spatial variants, ambiguous identification, and low different features of backscatter [2]. Especially for the propagation space, electromagnetic waves propagated through the ionosphere interact with electrons and magnetic fields.

The full characteristic of backscattered SAR signal from random object only can be passed by using circular polarization. If it is compared with the linear SAR sensor, then a large amount of information about the scene and the image target will be provided by a Circularly Polarized-Synthetic Aperture Radar (CPSAR) sensor [3].

The synthesis result of circularly-polarized data are better than the conventional linearly-polarized data. The CP-SAR sensor can detect the presence of object from long distance, the speed of object, the specific interest map of object, such as monitoring the condition of hazards (earthquake, flood, tsunami, volcanic eruption, forest fire), monitoring the oceans (ocean wave, offshore oil drilling), mapping the surface contour (the area classification of forest and non-forest, the height approximation of tree, the extraction of the wet area and agricultural area, the map of mangrove area, the detection of snow and glacier), determining floristic composition (content and type of substance on flora) [4]. To realize the high quality and efficiency in these applications, the CPSAR parameters including size, weight, power consumption, and type of substrate material should be thoroughly considered [2]. One of the solutions related to CP-SAR parameters is microstrip antenna that can be integrated with CP-SAR system.

Therefore, in this paper we will design a basic construction of radar microstrip antenna at the $S$ band frequency with low power on geostationary satellite. The substrate material of this radar antenna is made from microstrip material whose relative permittivity, $\varepsilon_{r}=2.17$ and loss tangent, $\delta=0.0009$ for obtaining high resolution and good image for any explored terrain. As compared with conventional microwave antennas, a microstrip antenna has additional advantages such as a compact size, lightweight, conformability of the substrate surface, low cost, easier to integrate with other circuits, flexible, and well established. Hence, it is suitable for the attached radar antenna on the body of geostationary satellite or the other aircraft in which be able to achieve the need of communication infrastructure that has variety platform and capable to produce the processed data with high quality and good efficiency.

This paper discuss only three types of microstrip antenna i.e. truncated-tip without and with slot, and equilateral triangle antennas as a basic for array antenna that are needed for CP-SAR application with low-power and located on the body of geostationary satellite. The performance of these antennas is circular polarization. This condition make them easier to capture image of object on earth when applying the array configuration. These antennas are compared and analyzed together according to the unique structure of one another.

In this investigation, only the numerical simulation related to the microstrip antennas are performed, then the results of them are discussed. In particular, the analysis focuses on the study of the comparison of three types of antenna, namely truncated-tip without and with slot, and equilateral triangle antenna. Truncated-tip without slot antennas are cl, scope 
(c2), and hexagonal (c3), while truncated-tip with slot antenna is c3s. All of them can be applied for remote sensing application embedded on geostationary satellite after optimized and configured to array antenna $[5,6,7,8]$.

The Method of Moments (MOM) is chosen in the numerical analysis for fast calculation. The software used is Ensemble ${ }^{\mathrm{TM}}$ version 8 from Ansoft [9]. The numerical simulation (c1, c2, c3, c3s, and equilateral triangle antennas) and the measurement results (only equilateral triangle antenna) of the antenna configuration are shown, especially at the frequency around $2.5 \mathrm{GHz}-2.9 \mathrm{GHz}$ as a basic construction of array antenna embedded on geostationary satellite for CP-SAR application. Table 1 shows the specification and the desired target for the CP-SAR system, which in turn influence the specification of the S-Band CP-SAR geostationary satellite antenna [2]. Each antenna can generate wave that yield a Circular Polarization (CP). The technique to achieve CP can be easily obtained i.e. by properly adjusting the element parameters, determining locus feed, and designing stub-fed $[6,10,11]$. Therefore, in the simulation of equilateral triangle antenna, the significant variation performances are also affected by stub-fed, especially S-parameter, frequency characteristic, input impedance, and radiation pattern. The performances are compared with the realized measurements using a network analyzer HP $8510 \mathrm{C}$ in the radio anechoic chamber.

Table 1 Technical Specification of CP-SAR System

\begin{tabular}{lll}
\hline No & Antenna Parameter & \multicolumn{1}{c}{ Specification CP-SAR System } \\
\hline 1. & Frequency $(f)(\mathrm{GHz})$ & L-band: $1.25-1.27 ;$ S-band: $2.5-2.9$ \\
2. & Pulse Band Wide $(\mathrm{MHz})$ & $10-233.31$ \\
3. & Axial Ratio $(\mathrm{dB})$ & $\leq 3$ \\
4. & Antenna Efficiency $(\%)$ & $>80$ \\
5. & Gain Antenna (dBic) & $14.32-36.6$ \\
6. & Azimuth Beamwidth $\left({ }^{\circ}\right)$ & $\geq 1.08$ \\
7. & Elevation Beamwidth $\left({ }^{\circ}\right)$ & $\geq 2.16$ \\
8. & Antenna Size $(\mathrm{m})$ & 2 (azimuth) $\times 4$ (range/elevation) \\
9. & Polarization $(\mathrm{Tx} / \mathrm{Rx})$ & $\mathrm{RHCP}+$ LHCP \\
\hline
\end{tabular}

\subsection{METHODOLOGY}

The conducting patch can be formed into several shapes, but rectangular and circular configurations are the most commonly used. The shape that the much attracting lately is the triangle shape of patch antenna. It is due to its small size compared with other shapes like the rectangular and circular patch antennas. Moreover, the triangle shape is chosen since it can easily be arranged and fabricated to produce CP radiation. The single element patches which have been optimized are then spatially arranged to form a planar array [11]. The planar array configuration is widely employed in radar systems where a narrow pencil beam is needed. A better control of the beam shape and position in space can be achieved by correctly arranging the elements along a rectangular grid to form a planar array (see Figure 1) $[3,11]$.

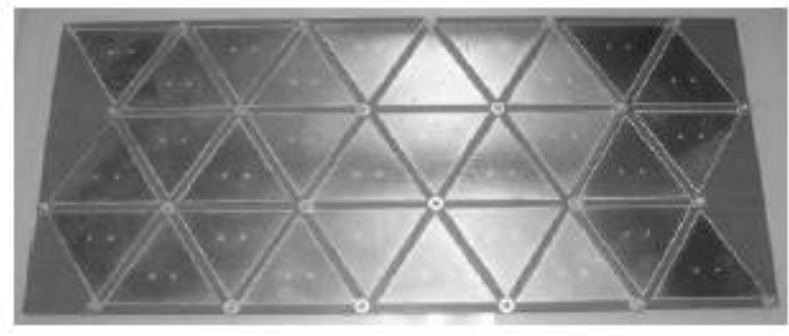

Figure 1 Miniature of a CP-SAR triangle array antenna consisting of microstrip elements

For the ease discussion in this paper, we separate the explanation into three parts namely (i) the model c2 and c3 antennas, (ii) the model c1, c3, and c3s antennas, (iii) the model equilateral triangle antenna. Actually the c3 antennas in the part (i) and (ii) are similar but not same, especially in parameter sizes of antenna that affect the difference of resonant frequency of antenna i.e. $2.5 \mathrm{GHz}$ and $2.9 \mathrm{GHz}$, respectively.

In section 2.0, we discuss about the characteristic configuration of each part. Then in section 3.0, we explain about the comparison of each part. In this section, we focus on the design of a triangle patch antenna as the basic construction to form a planar array that uses probe feed and microstrip-line feed. Among these models, the model of equilateral triangle antenna using dual feed type one is more appropriate to conduct a multi-polarization (LHCP = Left Hand Circular Polarization and RHCP = Right Hand Circular Polarization) array because it is loaded with isolation parameter compared to probe feed. Then, we select the model of equilateral triangle with microstrip-line dual feed type one to discuss more detail (including simulation, fabrication, and measurement) rather than the model c1, c2, c3, and c3s (only simulation). A microstrip-line dual feed equilateral triangle microstrip element antenna has superior properties and would be a good element for the CP-SAR implementation.

\subsection{Model c2 and c3 Antennas}

Figure 2 and Figure 3 show the configuration of model c2 and c3 antennas, respectively. The equilateral triangle patch antenna has a side length, $a=b$ and $a$ conventional substrate (relative permittivity, $\varepsilon_{r}=2.17$ and loss tangent, $\delta=0.0009$ ) [12]. The configuration of these antennas involve the cutting from each of the tip of an equilateral triangle patch antenna. We call these cutting as $I p$ and $I s$. The function of $I p$ is to make a perturbation for achieve the CP. Furthermore, the function of truncated-tips is is to create a new phenomenon relatively for each antenna, for 
example in the c2 antenna if $1 s<1 p$ or in the $c 3$ antenna if $I s>$ Ip, that are LHCP and RHCP occur when probe feed are located on the right and the left side of the equilateral triangle patch antenna, respectively. In addition, LHCP can be obtained as follow: the effective current distribution that arise from the patch surface on the $y$ direction is slightly shorter than in the $x$ direction, which gives the $y$-directed resonant frequency slightly larger than the $x$-directed resonant frequency with equal amplitudes and $90^{\circ}$ phase differences in the right side of the antenna. In the other hand, RHCP can be achieved in the opposite manner. Further, the function of two truncated-tips with length is role as switching to change the variation of polarization, if the probe feed exist on the same place (for example probe-fed take place in the right side, if $I s>I p$ and $I s<1 p$ for $c 2$ and $c 3$ antennas, respectively, then RHCP occur on that place). If Is $=1 p$, then both of $c 2$ and $c 3$ antennas do not have circular polarization, only linear polarization can be obtained [6].

Moreover, the function of Is can also affect the impedance and the axial ratio bandwidth. It makes the impedance bandwidth become narrow but the axial ratio bandwidth become wider and smoother than without Is (seen in Figure 7).

The Method of Moments in this paper is employed to simulate the model antennas with infinite ground plane. The consideration of the efficient thickness of the antennas (seen in Figure 2 and Figure 3) allow the substrate thickness for equilateral triangle patch to be defined, that are called as single layer $(h=1.6 \mathrm{~mm})[5$, 6]. The results for both $c 2$ and $c 3$ antennas are compared to know the improvement performance of each antenna.

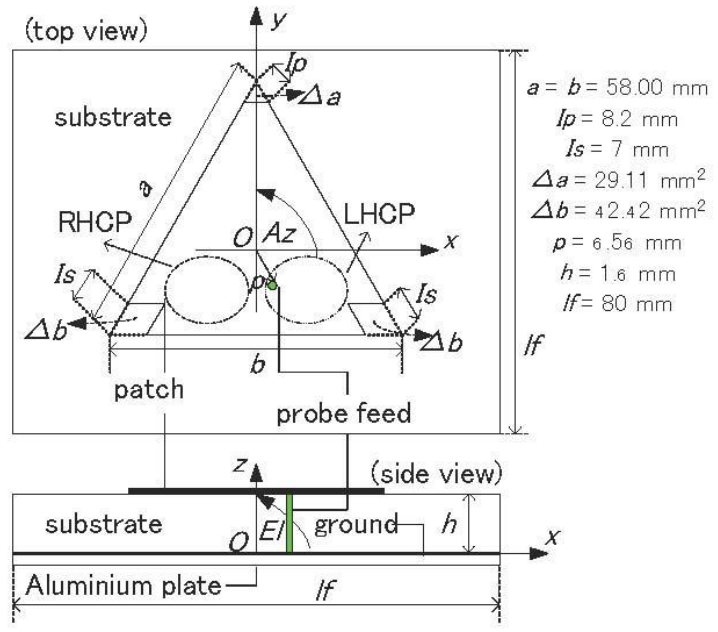

Figure 2 Configuration of c2 antenna

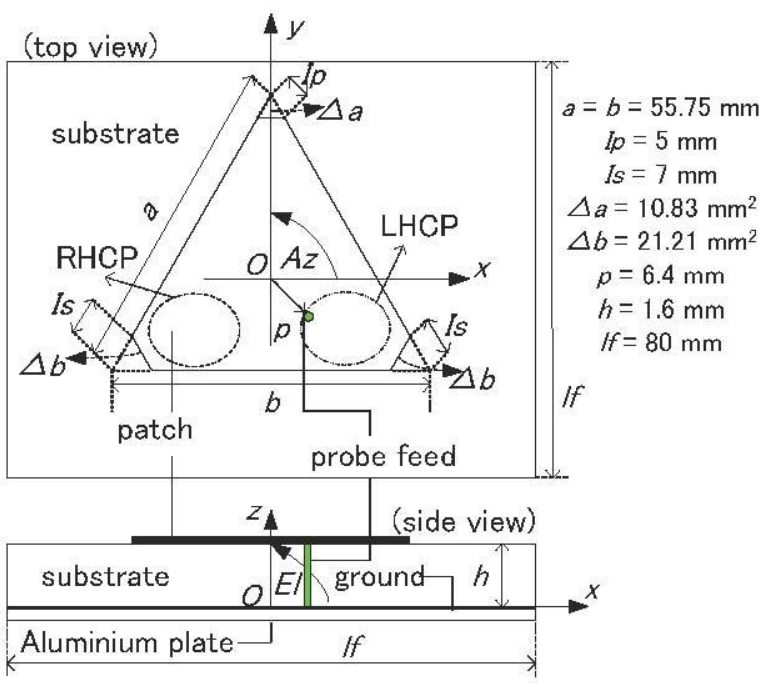

Figure 3 Configuration of c3 antenna

\subsection{Model c1, c3, and c3s Antennas}

Figure 4 shows the configuration of $c 1, c 3$, and c3s antennas design. The equilateral triangle patch has a length, $a=b$ and a conventional substrate $\left(\varepsilon_{r}=2.17\right.$ and $\delta=0.0009$ ). The antenna is fed by single probe located on right side for CP. The side length construction of model $\mathrm{cl}, \mathrm{c} 3$, and $\mathrm{c} 3 \mathrm{~s}$ antennas are the same size, $a=b$. In this case, $c l$ antenna is without slot on the ground plane and Is, while c3 antenna use Is but no slot on the ground plane, and the last one, c3s has both Is and slot on the ground plane. Hence, to show all of these antenna configurations, we make their in one figure as seen in Figure 4. The function of Ip is to make a perturbation for achieve the CP. Furthermore, the function of truncated-tips Is are to create a new phenomenon relatively for each antenna, for example in the c3 and c3s antennas if is $>$ Ip, then LHCP and RHCP are obtained as probe feed located on the right and the left side of the equilateral triangle patch antenna, respectively. Otherwise, in the cl antenna if $I s=0<I p$, then LHCP and RHCP occur when probe feed is located on the left and the right side, respectively. As well, the function of Is serve as switching to change the variation of polarization, if the probe feed is located on the same place (for example probe feed locus in the right side, if $I s<I p$ for both $c 3$ and c3s antennas, then RHCP will be achieved on that place). If Is $=1 p$, then both of $c 3$ and c3s antennas do not have circular polarization and only obtain a linear polarization [6].

In addition, LHCP and RHCP for $\mathrm{c} 3$ and $\mathrm{C} 3 \mathrm{~s}$ antennas can be obtained in the same manner with section 2.1. However, in case cl antenna, the effective current distribution that rise from the patch surface in the $y$-direction is slightly longer than in the $x$ direction, which gives the $y$-directed resonant mode slightly smaller than the $x$-directed resonant mode [7]. Hence, the dominant mode (TM 10 mode) of the $c l$ antenna can be split into two near-orthogonal resonant modes with equal amplitudes and $90^{\circ}$ phase 
difference for LHCP operation in the left side of the antenna. Also, RHCP can be attained in the opposite manner of $\mathrm{cl}$ antenna [8].

The slot of c3s antenna embedded on the ground plane (seen in Figure 4) causes the decrease of bandwidth antenna, but the advantage of this technique is to make the antenna become smaller than other [13]. Furthermore, the function of slot is to decrease the frequency operation where the current path or guide wavelength, $\mathrm{\lambda g}$ of the $\mathrm{TM} 10$ mode with slot is longer than the current path without slot. Hence, the purpose of c3s antenna is to yield the optimal result including the small antenna and the slightly wide bandwidth.

Moreover, the annular sector slot is embedded on the ground plane with the width of radial, $w=1 \mathrm{~mm}$. This is meant that the operation frequency decreases, so the antenna can be designed smaller than the previous antennas, $c 2$ and c3 in the section 2.1 [14]. In addition, the annular sector slot can appear in the other modes ( $\mathrm{TM}_{20}$ and $\mathrm{TM}_{30}$ ) at the higher operation frequency. Placing of this slot on around of the ground plane can affect the current path surface and the performance of antenna. The result of c3s antenna is compared with the other result of $\mathrm{cl}$ and $\mathrm{c} 3$ antennas to know the improvement performance of each antenna.

One of the most common techniques for calculating the unknown current of the patch antenna is the Method of Moments. This method discretizes the integral into a matrix equation which can then be solved. This discretization can be considered as dividing the antenna surface into a number of small elements. From the current distribution, the S-parameter, radiation pattern and any other parameters of interest can be obtained.

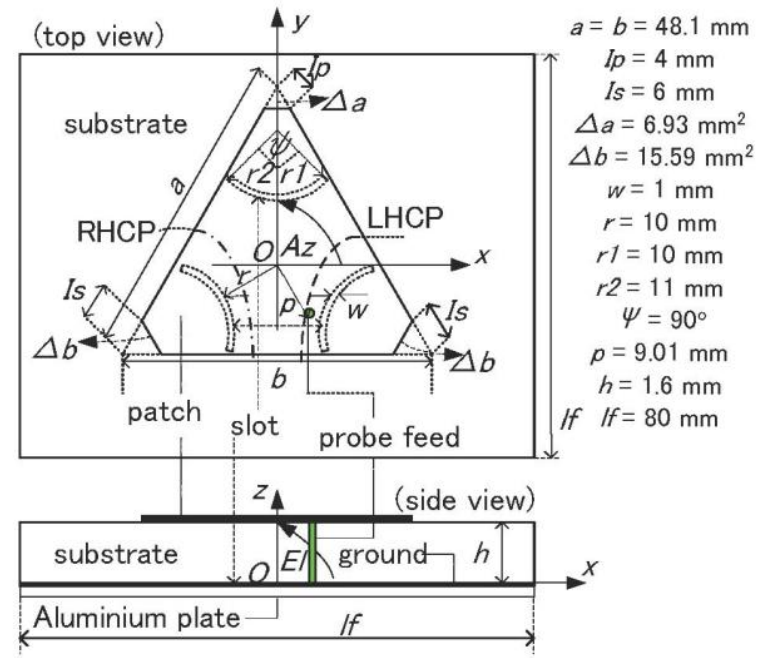

Figure 4 Configuration of $\mathrm{cl}, \mathrm{c} 3$ and $\mathrm{c} 3 \mathrm{~s}$ antennas

\subsection{Model Equilateral Triangle Antenna}

Figure 5 depicts the configuration of an optimized single equilateral triangle patch antenna with its parameters. The patch antenna is fed by microstrip- line to obtain a thin configuration. The purpose of dual feed type one is to generate LHCP by using equilateral triangle patch antenna without truncated-tips, which one of the microstrip-line feed is longer than the other to introduce a $90^{\circ}$ phase delay. In the same manner, RHCP can be realized by swapping the microstrip-line to $y$-axis. The design of feeding technique is to obtain an ideal and stable current distribution on the triangle patch surface that improve the previous developed antennas such as c1,c2, c3, and c3s antennas [15, 16].

The antenna is made of a thin conducting patch that the radiating patch and microstrip-line feed are located on the same layer which has thickness, $h=1.6$ $\mathrm{mm}$ and uses a conventional substrate $\left(\varepsilon_{r}=2.17\right.$ and $\delta=0.0009) \quad[5,6,12,16,17]$. The quarter-wave transformer is used to obtain a matching impedance of $50 \Omega$ for Transmitter/Receiver (Tx/Rx). The fabricated antenna also can be seen at Figure 6 . The height and width of ground plane are about $80 \times 80 \mathrm{~mm}$. Then, we compare the simulation and measurement results of equilateral triangle antenna, in order to prove the consistency of these results.

The antenna analysis using the Method of Moments is based on the calculation of the magnetic vector potential $\boldsymbol{A}$ and the electric scalar potential $\Phi$, assuming the electric current on the antenna, or the density of current, to be an unknown variable. Let assume from here that the dependence in time is sinusoidal. Hence, $\boldsymbol{A}$ and $\Phi$ can be calculated from the following equations by assuming that current flows on the antenna and the sources are electric charges [6]:

$$
\begin{aligned}
& A=\mu \iint_{V} J \Phi d V \\
& \Phi=\frac{1}{\varepsilon} \iint_{V} \rho \varphi d V
\end{aligned}
$$

Here, $\mu$ is the magnetic permeability, $\varepsilon$ is the permittivity, $\varphi$ is the elementary solution, and $V$ is the region of the antenna. In three dimensional problems, the elementary solution is given by

$$
\varphi=\frac{1}{4 \pi r} \exp (-j k r)
$$

Considering $\boldsymbol{J}$ and $\rho$ not being independent, from the Gauss's Law, we have

$$
\nabla \cdot D=\rho
$$

And from the time differential of the density of magnetic flux $\boldsymbol{B}$, i.e. from the equation that expresses the divergence of Ampere's Law and ignoring the current charges, we get

$$
\nabla \cdot J+\nabla \cdot \frac{\partial D}{\partial t}=0
$$

which $\rho$ is connected. From the equation of the electric continuity, the following equation can be obtained 


$$
\rho=-\frac{\nabla \cdot J}{j \omega}
$$

When $\boldsymbol{J}$ and $\rho$ conform to the upper equation, the obtained expressions of $\boldsymbol{A}$ and $\Phi$ satisfy Lorenz's gauge. The strength of electric field $\boldsymbol{E}$ is derived from $A$ and $\Phi$ :

$$
E=-j \omega A-\nabla \Phi
$$

Finally, at the surface of the antenna, i.e. the surface of a perfect conductor where the tangential component of $\boldsymbol{E}$ tends to zero, the following equation needs to be used in order to create the system of equations:

$$
-n \times E=n \times E_{0}
$$

where $\boldsymbol{n}$ is the normal direction, $\boldsymbol{E}_{0}$ the outer electric field. By substituting (7) into (8), the next equation is obtained

$$
j \omega A+\nabla \Phi=n \times E_{0}
$$

\subsection{RESULTS AND DISCUSSIONS}

In general, the discussion of single element antenna is limited only in electric field. Especially for far-field or called as radiation characteristic, the elevation plane is mostly described rather than azimuth plane. As we know that the angle $\phi$ denote $X-Y$ or azimuth or magnetic field plane (move from $0^{\circ}$ in positive $X$-axes and rotates $360^{\circ}$ ) and $\theta$ indicate elevation or electric field plane (stir from $0^{\circ}$ or elevation angle, $E I=90^{\circ}$ in positive Z-axes to negative Z-axes exactly $180^{\circ}$ or $E l=$. $\left.90^{\circ}\right)$. There are two types electric field plane i.e. (i) electric field vertical correlate to $\phi=0^{\circ}$ and $\theta$ varies ( $X$ $Z$ plane) (ii) electric field horizontal correlate with $\phi=$ $90^{\circ}$ and $\theta$ varies ( $Y-Z$ plane). Because the model equilateral triangle antenna using dual feed type one be a good element for the CP-SAR implementation, so this model is examined both simulation and measurement including azimuth plane with $\theta=0^{\circ}$ and $\phi$ varies (the maximum beam for single element in $X-Z$ and $Y-Z$ plane). But the other antennas are adequate discussed until elevation plane both for $X-Z$ and $Y-Z$ plane. All of the graphs use Cartesian coordinate that is better than Polar coordinate, especially for describing $C P$ that represent the values of axial ratio below $3 \mathrm{~dB}$. Also, the azimuth plane which reflects the direction of wave propagation is described easier in Cartesian coordinate. In this section, we discuss all of the model antennas related with frequency characteristic, S-parameter, input impedance characteristic, and radiation characteristic (elevation plane).

\subsection{Comparison of Model c2 and c3 Antenna}

Figure 7 to Figure 9 show the simulation result of the truncated-tip of $c 2$ and c3 antennas, in case of frequency characteristic, S-parameter, and input impedance. Figure 7 shows that the values of gain and axial ratio (Ar) for simulation of the truncated-tip of $c 2$ and $c 3$ antennas at the resonant frequency 2.5 $\mathrm{GHz}$ are almost same around $6.8 \mathrm{dBic}$ and $0.42 \mathrm{~dB}$, respectively. In addition, the bandwidth $(\Delta W)$ of axial ratio and gain both of $c 2$ and $c 3$ antennas are also slightly same about $0.0143 \mathrm{GHz}$ or $0.572 \%$ and $0.08 \mathrm{GHz}$ or $3.2 \%$, respectively.

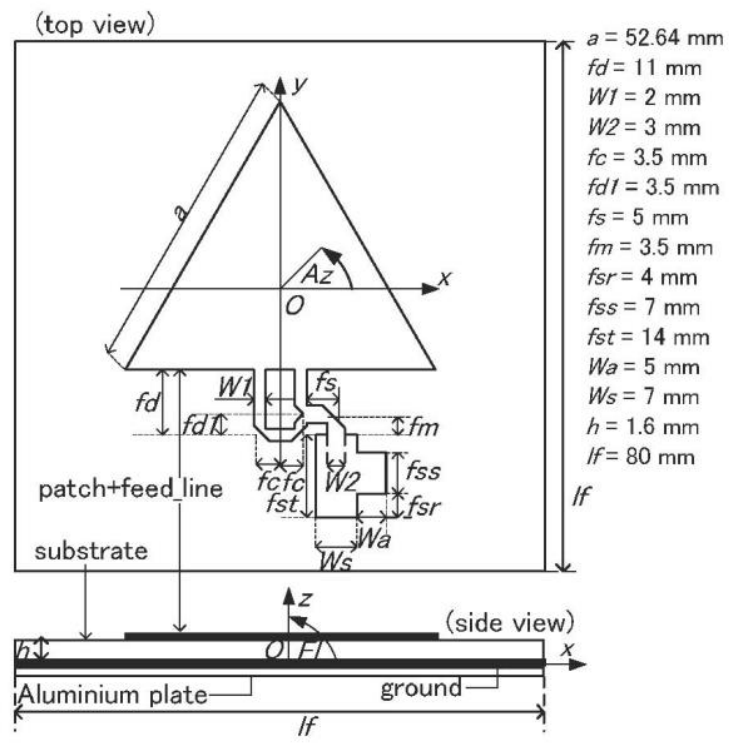

Figure 5 Configuration of equilateral triangle antenna

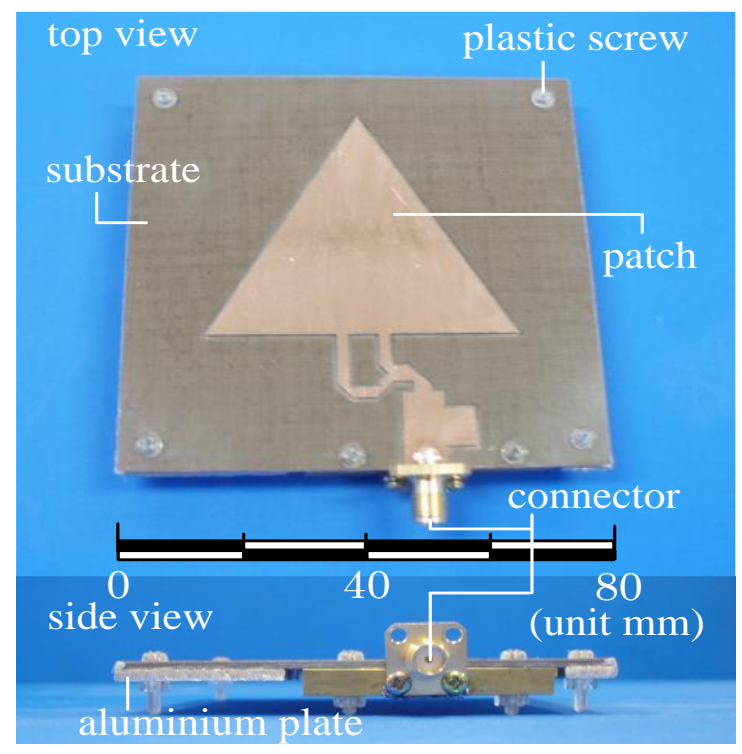

Figure 6 Fabricated of equilateral triangle antenna 


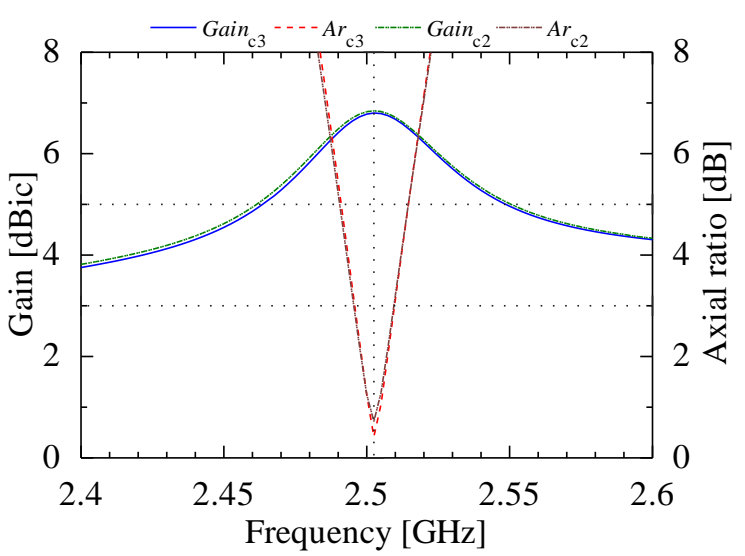

Figure 7 Frequency characteristic of $c 2$ and c3 antennas

Figure 8 shows the relationship between the reflection coefficient (S-parameter) and frequency for the $T x / R x$ antenna simulation. From this figure, it can be seen that the $S$-parameter of the truncated-tip c2 antenna at the resonant frequency is better than the truncated-tip c3 antenna, namely about -23.7 dB and $-17.9 \mathrm{~dB}$, respectively. But the bandwidth impedance below -10 dB for both $\mathrm{c} 2$ and $\mathrm{c} 3$ antennas are little bit different, around $0.05 \mathrm{GHz}$ or $2 \%$. This case is caused by loci of each feeding antenna (c2 and c3) that already optimized on the properly place. Furthermore, it is also affected by perturbation area on the both sides of each antenna (Is) which can reduce the $S$ parameter bandwidth.

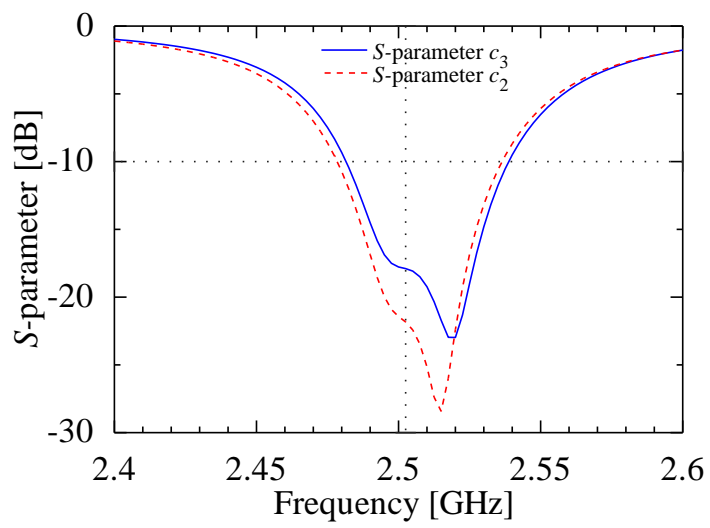

Figure 8 S-parameter of $c 2$ and $c 3$ antennas

Figure 9 depicts the input impedance characteristic of $T x / R x$. This figure shows the real part of each antenna simulation that slightly same for each antenna, that is approximately $50 \Omega$ at the operation frequency. Moreover, the reactance part of the truncated-tip c2 and c3 antennas are also little bit same, around $0 \Omega$ at the resonant frequency.

For probe feed antenna, the input impedance depend on the feed position. The variation of input impedance at the resonant frequency with feeding position follow the cavity field. In the lowest mode, it is usually large when the feeding is near the edge of the patch and decreases as the feeding moves into the patch. Its magnitude can be varies from tens to hundreds ohms. By choosing the feeding position properly, an effective matching between the antenna and the transmission-line can be obtained $[17,18]$.

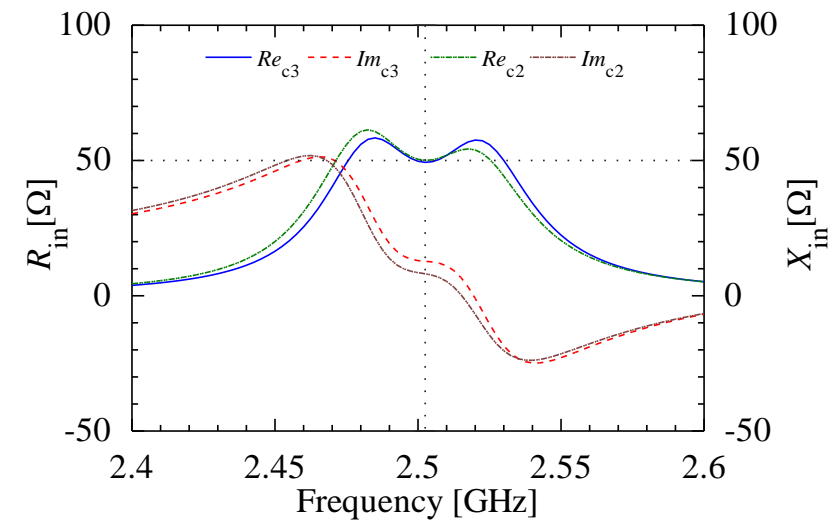

Figure 9 Input impedance of c2 and c3 antennas

Figure 10 and Figure 11 depict the relationship between gain-axial ratio and elevation angle at $A z=$ $0^{\circ}$ and $A z=90^{\circ}$. At the elevation, $E I=90^{\circ}$ the maximum gain of $c 2$ and $c 3$ antennas are about $6.68 \mathrm{dBic}$ in both of azimuth angles. But, they are little bit different for axial ratio, both in $X-Z$ and $Y-Z$ planes, about 0.83 $\mathrm{dB}$ and $0.29 \mathrm{~dB}$ for each $\mathrm{C} 2$ and $\mathrm{C} 3$ antenna at $E \mathrm{I}=90^{\circ}$. From this results, we can note that the effect of the use of truncated-tip for both c2 and c3 antennas related to the performances result are similar. But, only the axial ratio results are little bit different each other.

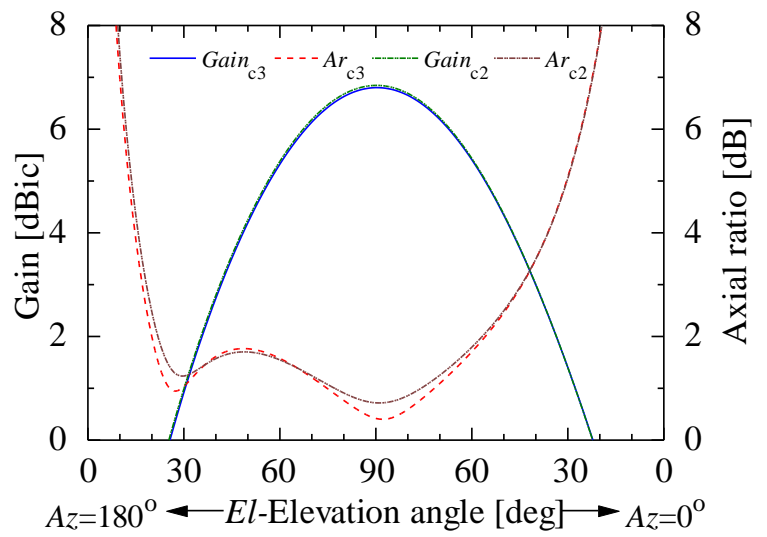

Figure 10 Radiation characteristics $(X-Z)$ of $c 2$ and $c 3$ antennas at $f=2.5 \mathrm{GHz}$ 


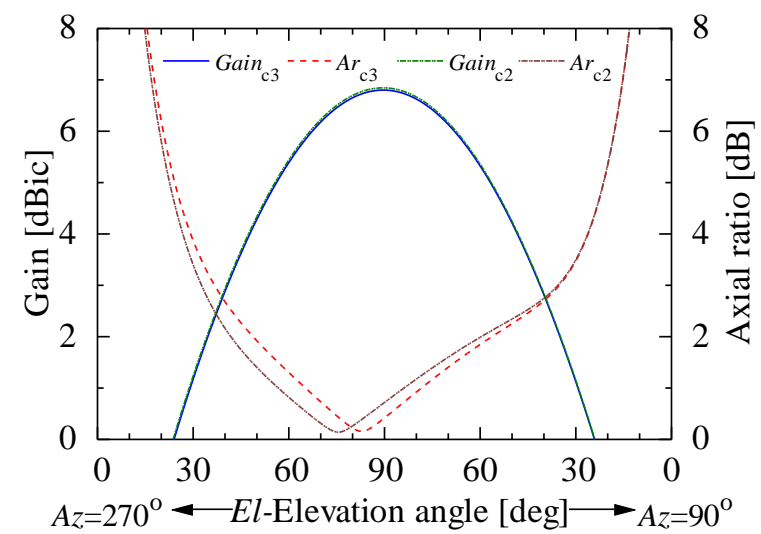

Figure 11 Radiation characteristics $(Y-Z)$ of $c 2$ and $c 3$ antennas at $f=2.5 \mathrm{GHz}$

\subsection{Comparison of Model c1, c3, and c3s Antennas}

Figure 12 to Figure 14 show the simulation results among $\mathrm{cl}, \mathrm{c} 3$ and $\mathrm{c} 3 \mathrm{~s}$ antennas, in the case of frequency characteristic, S-parameter, and input impedance. The bandwidth of c3 antenna is the widest. The bandwidth of c3s antenna is almost same with $\mathrm{cl}$ antenna. It is caused by using double truncated-tips is on the side of the patch antenna, thus the total of vector current distributions increase only around this area. For c3s antenna, the bandwidth decreases due to the use of annular sector slot embedded on the ground plane. Moreover, the bandwidth of $\mathrm{cl}$ antenna also decreases, because of the truncated-tip without $I s$, but this is slightly wider than c3s antenna.

Figure 12 shows the value of gain and axial ratio (Ar) for simulation of $\mathrm{cl}, \mathrm{c} 3$, and $\mathrm{c} 3 \mathrm{~s}$ antennas at the resonant frequency. The values are as follow: $\mathrm{cl}$ antenna operates at the frequency $2.76 \mathrm{GHz}$, gain RHCP $=6.66 \mathrm{dBic}, A r=2.91 \mathrm{~dB}$, the operation frequency of $\mathrm{C} 3$ antenna is $2.9 \mathrm{GHz}$, gain $\mathrm{LHCP}=6.98$ dBic, $A r=3.02 \mathrm{~dB}$, and for $\mathrm{c} 3 \mathrm{~s}$ antenna has the operation frequency equal $2.505 \mathrm{GHz}$, gain $\mathrm{LHCP}=$ $6.08 \mathrm{dBic}, \mathrm{Ar}=1.75 \mathrm{~dB}$. In addition, each antenna is fed by probe feed at the same loci on the patch antenna and the same size in which only appropriate for c3s antenna. It is clear that cl and c3 antennas do not satisfy the target yet, especially the axial ratio. It is because the loci of feeding still not maximize yet on the surrounding of patch antenna. Moreover, the gain c3s antenna at the resonant frequency is the lowest, because the annular sector slot embedded on the ground plane can decrease it. In addition, the gainbandwidth of c3 antenna is the widest compared with the other. This matter is owing to the use of truncatedtip is and without annular sector slot.

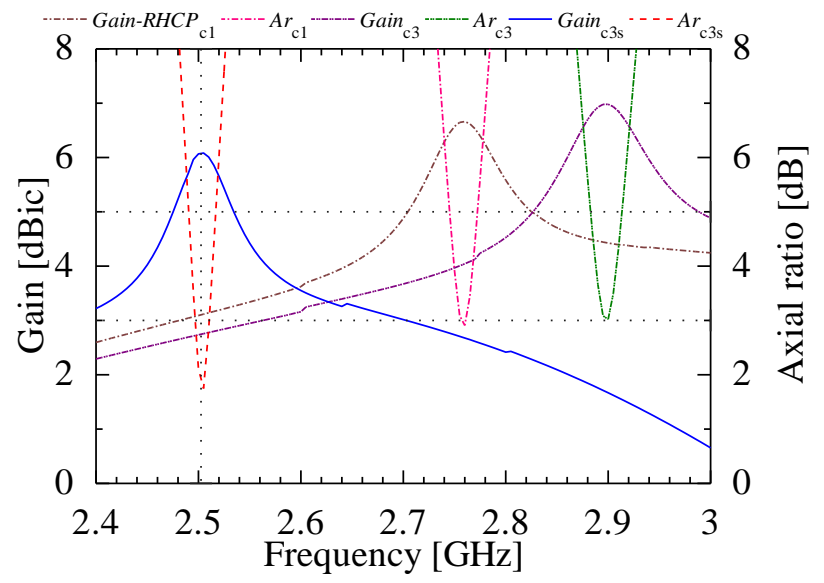

Figure 12 Frequency characteristic of $c 1, c 3$ and c3s antenna

Figure 13 shows the relationship between the reflection coefficient (S-parameter) and frequency for the simulation $T x / R x$ antenna. From this figure, it can be seen that the S-parameter of c3s antenna at the resonant frequency compared to the other $\left(S_{11-}-\mathrm{C}\right)=$ $13.55 \mathrm{~dB}$ and $\mathrm{S}_{11-\mathrm{C}} 3=-13.81 \mathrm{~dB}$ ) is the best about -21.07 $\mathrm{dB}$. It is caused by the use of annular sector slot and the location of this slot on the ground plane which is seem as the hyperbolic position respect to null potential or origin coordinate of antenna (seen in Figure 4). The S-parameter bandwidth of c3s antenna is the widest compared with the other. It is caused by the well-place of the optimized feeding loci of the patch antenna compared to the other [17]. In addition, it is also affected by the perturbation area at the both side of patch antenna (IS) that can enhance the S-parameter bandwidth.

Figure 14 depicts the input impedance characteristic of Tx/Rx antenna. This figure shows that both of the real and reactance parts of impedance are different each other. In case of c3s antenna, the real part approximate $50 \Omega$ at the frequency operation. Moreover, the reactance part of this antenna is the best compared to the other around 0 $\Omega$ at the resonant frequency.

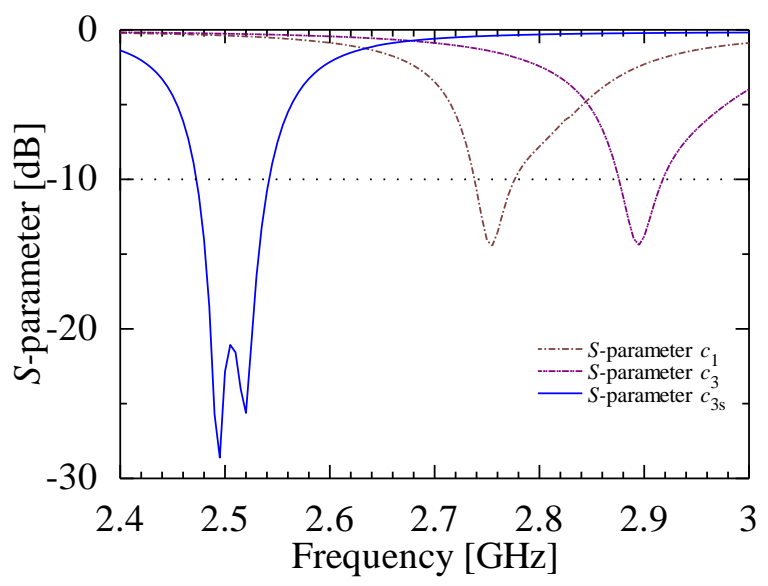

Figure 13 S-parameter of $c 1, c 3$ and c3s antennas 


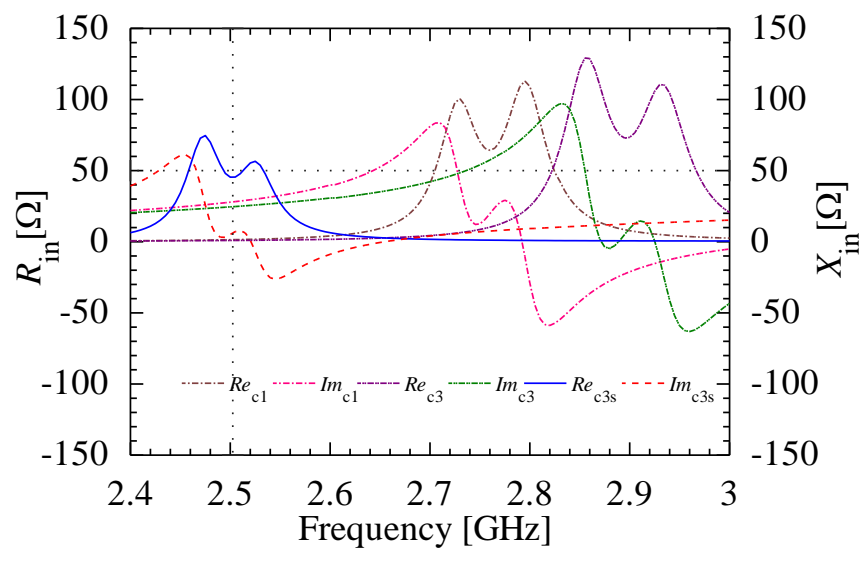

Figure 14 Input impedance of $c 1, c 3$ and c3s antennas

Figure 15 and Figure 16 depict the relationship between gain-axial ratio and elevation angle at $\mathrm{Az}=$ $0^{\circ}$ and $\mathrm{Az}=90^{\circ}$. At the elevation, $\mathrm{El}=90^{\circ}$ the maximum gain of $\mathrm{Cl}, \mathrm{c} 3$ and $\mathrm{c} 3 \mathrm{~s}$ antennas are consecutive of $6.66 \mathrm{dBic}, 6.98 \mathrm{dBic}$, and $6.08 \mathrm{dBic}$ in both of azimuth angles. While, the axial ratio of $\mathrm{cl}, \mathrm{c} 3$ and $\mathrm{c} 3 \mathrm{~s}$ antennas are relatively different each other at the $E I=$ $90^{\circ}$, in $X$-Z plane about $2.85 \mathrm{~dB}, 3.12 \mathrm{~dB}$ and $1.82 \mathrm{~dB}$, respectively. In the same case, the values of axial ratio at $Y$-Z plane are consecutively $2.25 \mathrm{~dB}, 2.53 \mathrm{~dB}$, and $1.82 \mathrm{~dB}$. Moreover, the axial ratio-beamwidth of $\mathrm{Cl}$, $\mathrm{C} 3$, and $\mathrm{c} 3 \mathrm{~s}$ antennas below $3 \mathrm{~dB}$ are different, in $X-Z$ plane around $10^{\circ}, 50^{\circ}$, and $90^{\circ}$, respectively. While, in $Y-Z$ plane they are consecutive of $60^{\circ}, 67^{\circ}$, and $80^{\circ}$. From this results, we can notify that the effect of the use of truncated-tip and annular sector slot embedded on the ground plane of c3s antenna at the resonant frequency and $E I=90^{\circ}$ make the axial ratio become better than the other, although its gain is relatively lower than the other.

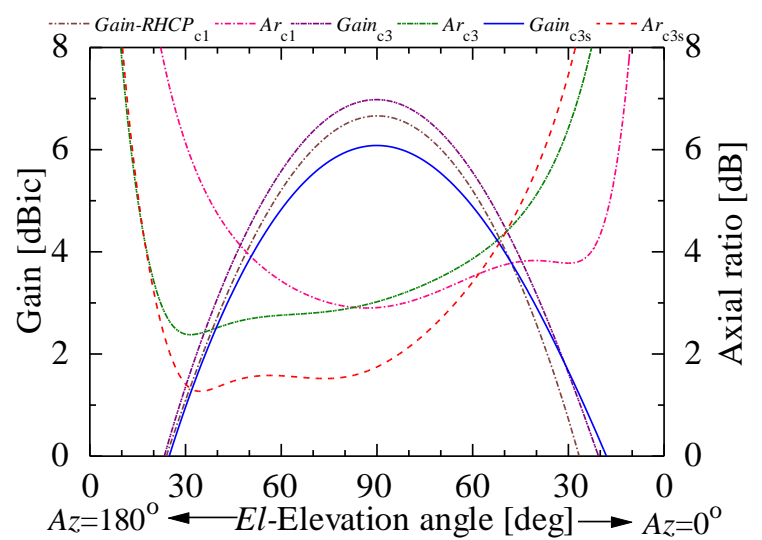

Figure 15 Elevation plane (X-Z) of $c 1, c 3$ and $c 3$ s antennas at $f=2.76 \mathrm{GHz}, f=2.9 \mathrm{GHz}$ and at $f=2.505 \mathrm{GHz}$, respectively

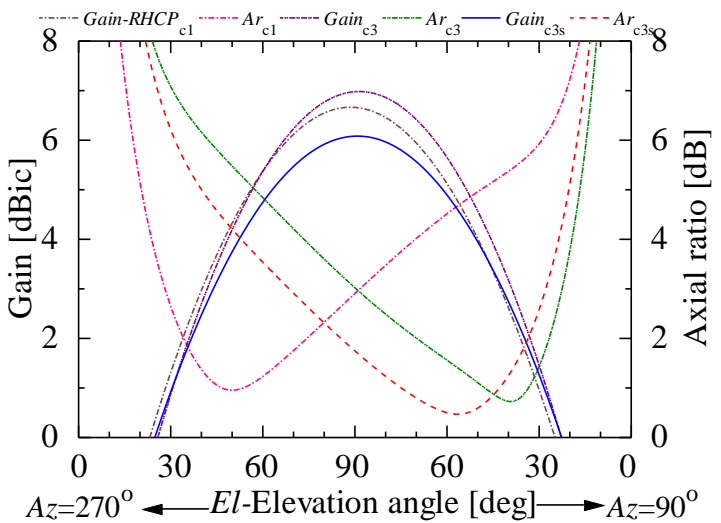

Figure 16 Elevation plane ( $\mathrm{Y}-\mathrm{Z}$ ) of $\mathrm{cl}, \mathrm{c} 3$ and $\mathrm{c} 3 \mathrm{~s}$ antennas at $f=2.76 \mathrm{GHz}, f=2.9 \mathrm{GHz}$ and at $f=2.505 \mathrm{GHz}$, respectively

\subsection{Comparison of Model Equilateral Triangle Antenna}

Figure 17 to Figure 21 show the result for both simulation and measurement in the case of frequency characteristic, S-parameter, input impedance and radiation characteristics. The difference between simulation and measurement that appears in the results is due to the effect of finite ground used in measurement while it is infinite by simulation.

Figure 17 shows that the value of axial ratio (Ar) measurement increases of about $18 \%$ compared to the simulation $(0.27 \mathrm{~dB}$ to $1.49 \mathrm{~dB})$, also the frequency is shifted about $0.9 \%(2.5 \mathrm{GHz}$ shifts to $2.53 \mathrm{GHz})$. This difference is due to the effect of the ground plane size, the antenna setting, the hole in the substrate, the connector, and the coaxial cables. Moreover, the bandwidth of axial ratio both simulation and measurement below $3-\mathrm{dB}$ consecutive of about 0.02 $\mathrm{GHz}$ or $20 \mathrm{MHz}$ and $0.015 \mathrm{GHz}$ or $15 \mathrm{GHz}$ meet for CPSAR geostationary satellite application.

Figure 18 shows the relationship between the reflection coefficient (S-parameter) and frequency for simulation and measurement of Tx/Rx antenna. From this figure, it can be seen that by comparison of the measurement with the simulation there is a frequency shifting about $1.5 \%$. In addition, the degree of agreement in the centre frequency is slightly different for the $-10 \mathrm{~dB}$ bandwidth. This difference is due to the fabrication error (e.g. drilling error about $0.1 \mathrm{~mm}$ ) and the influence of measurement system (connector, aluminium plate) [12]. In this case, utilization of the stub antenna strongly affects to influence a smoothly $S$ parameter, then satisfies the target. 


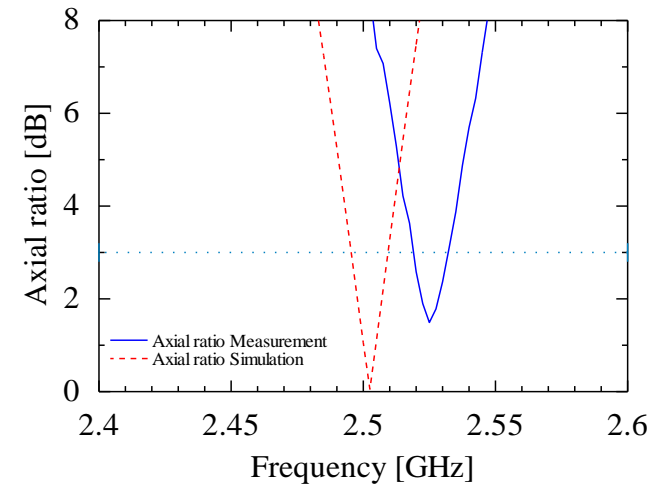

Figure 17 Axial ratio of equilateral triangle antenna

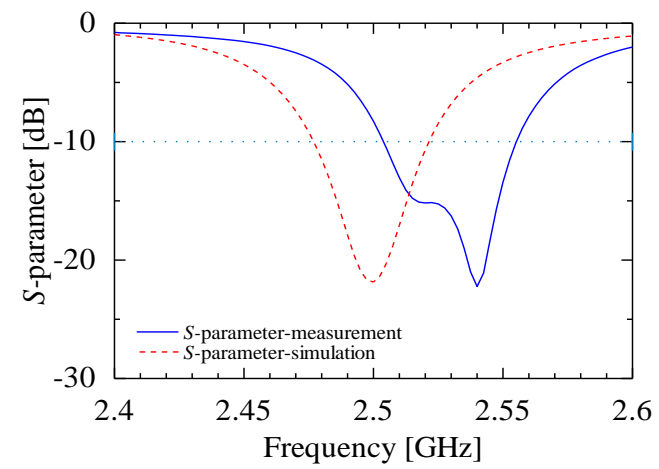

Figure $18 \mathrm{~S}$-parameter of equilateral triangle antenna

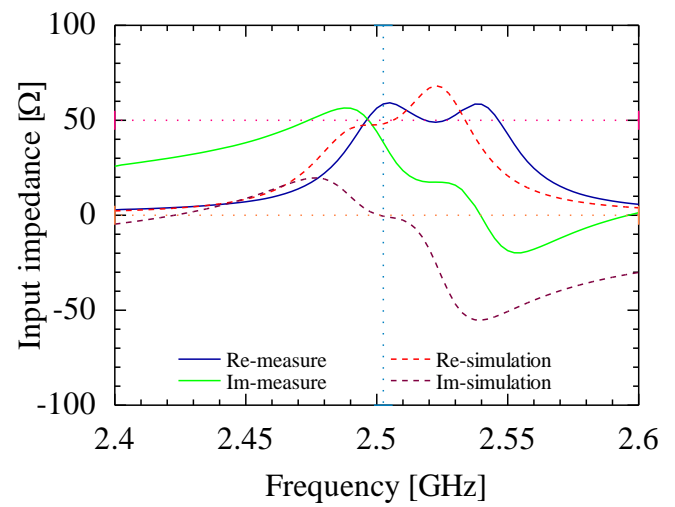

Figure 19 Input impedance of equilateral triangle antenna

Figure 19 depicts the input impedance characteristic of $T x / R x$. This figure also shows that the measurement result is shifted to the higher frequency from the simulation result by $0.7 \%$. In this case, the real part of measurement is $50 \Omega$.

Figure 20 and Figure 21 depict the relationship between gain-axial ratio and $\mathrm{El}$ in the $\mathrm{Az}=0^{\circ}$ and $90^{\circ}$ planes, respectively. In the $A z=0^{\circ}$, the maximum gain of simulation and measurement results are consecutively are $6.604 \mathrm{dBic}$ and $6.696 \mathrm{dBic}$ at the elevation, $E l=90^{\circ}$. These values are little bit different in the $A z=90^{\circ}$, especially for measurement result of gain i.e. $6.398 \mathrm{dBic}$. While, the axial ratio of simulation and measurement results are relatively different each other at the $E I=90^{\circ}$, in $X-Z$ plane about $0.05 \mathrm{~dB}$ and $2.068 \mathrm{~dB}$, respectively. In the same case, at $Y$ - $Z$ plane the axial ratio of simulation and measurement results are consecutively are about $0.049 \mathrm{~dB}$ and $1.71 \mathrm{~dB}$. Moreover, the $3 \mathrm{~dB}-\mathrm{Ar}$ beamwidth for simulation and measurement are consecutively are about $120^{\circ}$ and $80^{\circ}$. These values satisfy the targeted elevation beamwidth of $\geq 2.16^{\circ}$ at Table 1 (technical specification of CP-SAR system) for better resolution of CP-SAR geostationary satellite antenna.

The maximum gain obtained from the measurement result is similar with the simulation result, just a little bit different about $0.01 \mathrm{~dB}$. This is due to utilization of single layer antenna to reduce the various losses that occur during the measurement. In the case of axial ratio, there is no effect for the use of the single layer. It is caused by the use of a finite ground plane that strongly affects the radiation pattern, especially the axial ratio characteristics. The configuration of antenna and the measurement system, i.e. the coaxial cable, the connector, the hole, and the plastic screws in the substrates, are also considered to effect the current distribution on the patch surface, so that decrease the axial ratio performance $[12,17]$.

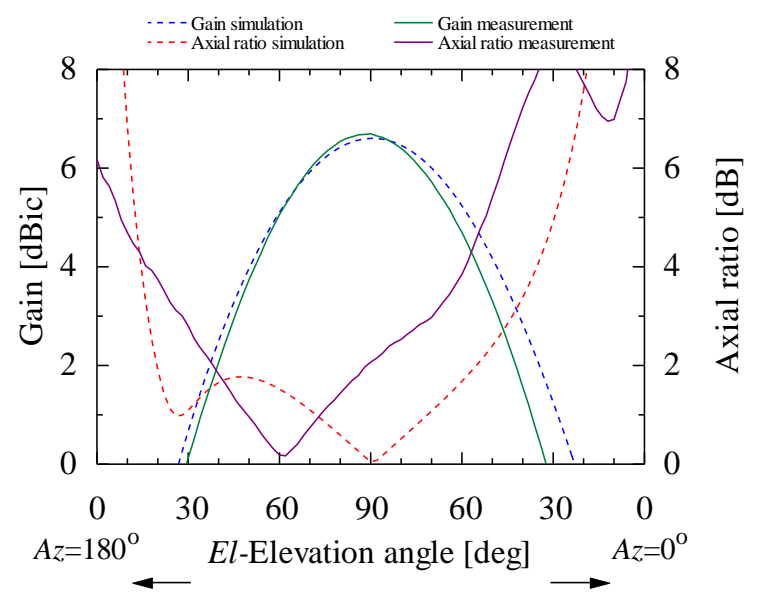

Figure 20 The $X-Z$ plane of equilateral triangle antenna at $f=$ $2.5 \mathrm{GHz}$ for simulation and at $f=2.53 \mathrm{GHz}$ for measurement

Figure 22 describes the characteristic of azimuth plane radiation generated by the equilateral triangle patch antenna using microstrip-line feed in the area of $E l=90^{\circ}$ or $\theta=0^{\circ}$ at resonant frequency of $f=2.5 \mathrm{GHz}$ for simulation and at $f=2.53 \mathrm{GHz}$ for measurement. From this figure, we can see that the peaks of the gain and the axial ratio both for simulation and measurement are the same for all of the azimuth angle or $\phi$ values i.e. $6.604 \mathrm{dBic}$ and $0.049 \mathrm{~dB}, 6.398$ $\mathrm{dBic}$ and $1.71 \mathrm{~dB}$, respectively. In addition, the values of the $3 \mathrm{~dB}-\mathrm{Ar}$ beamwidth cover perfectly the whole of $360^{\circ}$. This result exhibit that the targeted azimuth beamwidth of $\geq 1.08^{\circ}$ obtain the resolution of CP-SAR using geostationary satellite. 


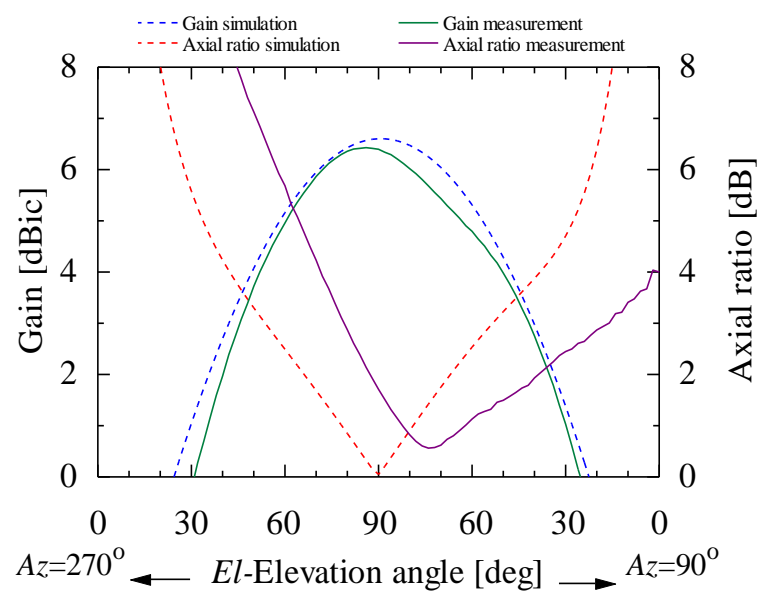

Figure 21 The $Y$ - $Z$ plane of equilateral triangle antenna at $f=$ $2.5 \mathrm{GHz}$ for simulation and at $f=2.53 \mathrm{GHz}$ for measurement

Elevation, $E l=90^{\circ}$ or $\theta=0^{\circ}$

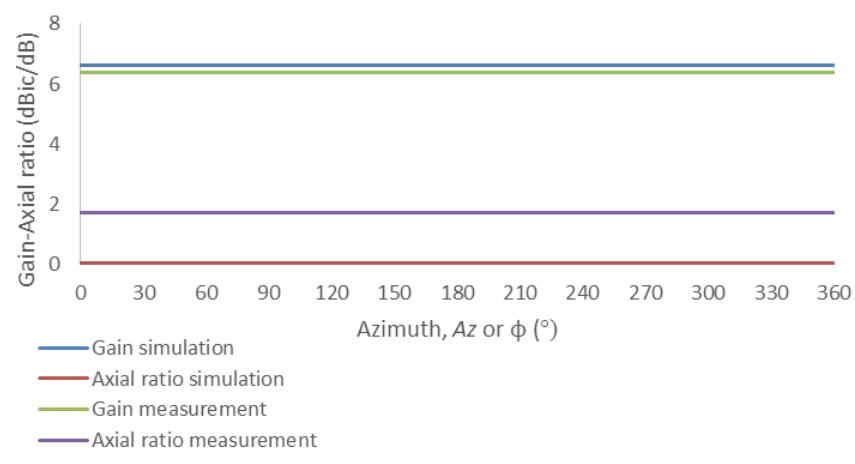

Figure 22 The $X-Y$ plane of equilateral triangle antenna at $f=$ $2.5 \mathrm{GHz}$ for simulation and at $f=2.53 \mathrm{GHz}$ for measurement

\subsection{CONCLUSION}

The analysis performances of triangle microstrip antenna at the S-band frequency with low power have been studied. In order to obtain a basic construction for CP-SAR geostationary satellite with compact, small, and simple configuration, the truncated-tip c1, c2, c3 and c3s antennas have been discussed. The performance results for $c 2$ and $c 3$ antennas are almost same. But, S-parameter and axial ratio in radiation pattern are different. Besides that, the truncated-tip of c2 antenna is smoother than c3 antenna. The performance results for $\mathrm{cl}, \mathrm{c} 3$, and c3s antennas at the each resonant frequency are relatively different. The whole result of performance characteristic of c3s antenna at operation frequency $2.5 \mathrm{GHz}$ is the smallest antenna size, although the axial ratio bandwidth decreases compared with the other. This matter is due to the annular sector slot of c3s antenna embedded on the ground plane. The results of simulation and measurement of equilateral triangle antenna, especially for axial ratio bandwidth below 3$\mathrm{dB}$ are about $0.02 \mathrm{GHz}$ or $20 \mathrm{MHz}$ and $0.015 \mathrm{GHz}$ or 15 $\mathrm{MHz}$, respectively. Furthermore, the $3 \mathrm{~dB}-\mathrm{Ar}$ beamwidth in elevation plane for simulation and measurement are consecutively about $120^{\circ}$ and $80^{\circ}$. Then, the $3 \mathrm{~dB}$-Ar beamwidth in azimuth plane cover perfectly the whole of $360^{\circ}$. These results temporarily meet the application of CP-SAR geostationary satellite.

\section{Acknowledgement}

The authors would like to express their gratitude to the Microelectronic Research Laboratory (MeRL), Electrical Engineering and Computer Science, Graduate School of Natural Science and Technology, Kanazawa University, Japan for the support to this research published in the journal. Also, the authors would like to thank the Laboratory of Antenna, Chiba University, Japan for the data of modeling and measurement used in this paper. Finally, special thanks to Ministry of Finance, Indonesia Endowment Fund for Education (LPDP) and Ministry of Research, Technology and Higher Education (RISTEKDIKTI) for the support of scholarship and publication.

\section{References}

[1] Chang, F. S., Wong, K.L. and Chiou, T. W. 2003. Low-cost Broadband Circularly Polarized Patch Antenna. IEEE Transactions on Antennas and Propagation. 51 (10): 30063009.

[2] Yohandri, et al. 2011. Development of Circularly Polarized Array Antenna for Synthetic Aperture Radar Sensor Installed on UAV. Progress in Electromagnetics Research C. 19: 119133.

[3] Baharuddin, M. et al. 2009. Equilateral Microstrip Antenna for Circularly-polarized Synthetic Aperture Radar. Progress in Electromagnetics Research C. 8: 107-120.

[4] Sumantyo, J. T. S. 2011. DInSAR Technique for Retrieving Volume Change of Volcanic Materials on Slope Area. IEICE Technical Report. 111 (239): 17-19.

[5] Purnomo, M. F. E. and Sumantyo, J. T. S. 2011. Design Circularly Polarized of Equilateral Triangular Hole Antenna for SAR (Synthetic Aperture Radar). IEICE Technical Report. 111 (239): 17-19.

[6] Purnomo, M. F. E. Suyono, H. Mudjirahardjo, P. and Hasanah, R. N. 2016. Analysis Performance of Singly-fed Circularly Polarized Microstrip Antenna for Wireless Communication. Jurnal Teknologi. 78(5-9).

[7] Purnomo, M. F. E. and Sari, S. N. 2012. Singly-fed Circularly Polarized Triangular Microstrip Antenna with Truncated Tip Using Annular Sector Slot for Mobile Satellite Communications. Proceedings EECCIS 2012. 172-EEC-35.

[8] Purnomo, M. F. E. Sumantyo, J. T. S. and Kusumasari, V. 2014. The Influence of Hole-truncated to Characteristic Performance of the Equilateral Triangular Antenna for Mobile Satellite. Proceedings of the IEEE. C3: 68-71.

[9] Ansoft Corporation. 2001. ANSOFT Ensemble User Guide Manual (ver. 8)

[10] Tang, C. L. Lu, J. H. and Wong, K. L. 1998. Circularly Polarized Equilateral-triangular Microstrip Antenna with Truncated Tip. Electron. Letter. 34: 1227-1228.

[11] Purnomo, M. F. E. Rahmadwati, R. Suyono, H. Yuwono, R. And Sumantyo, J. T. S. 2016. Development L-Band Antena with Low Power for Circularly Polarized-Synthetic Aperture Radar (CP-SAR) Application on Unmanned Aerial Vehicle (UAV). Proceedings of The 7th Indonesia Japan Joint Scientific Symposium. The 24th CEReS International Symposium. The 4th Symposium on Microsatellite for 
Remote Sensing(SOMIRES 2016). The 1st Symposium on Innovative Microwave Remote Sensing. Keyaki Convention Hall. 392-403.

[12] Sumantyo, J. T. S. and Ito, K. 2004. Simple Satellite-tracking Triangular-patch Array Antenna for ETS-III Applications. IEICE Tech.Rep., AP2003-236.

[13] Iwasaki, H. 1996. A Circularly Polarized Small-size Microstrip Antenna with a Cross Slot. IEEE Trans. Antenna Propagation. 44: 1399-1401.

[14] Ishihara, H. Yamamoto, A. and Ogawa, K. 2002. A Simple Model for Calculating the Radiation Patterns of Antennas Mounted on a Vehicle Roof. Interim International Symposium on Antenna and Propagation. 548-551.

[15] Sumantyo, J. T. S. Ito, K. and Takahashi, M. 2005. Dual-Band Circularly Polarized Equilateral Triangular-Patch Array
Antenna for Mobile Satellite Communications. IEEE Transactions on Antennas and Propagation. 53(11).

[16] Suzuki, Y., Miyano, N. and Chiba, T. 1987. Circularly Polarized Radiation From Singly Fed Equilateral-Triangular Microstrip Antenna. IEE Proceeding. 34: 194-197.

[17] Wong, K. L. and WU, J. Y. 1997. Single-feed Small Circularly Polarized Square Microstrip Antenna. Electron. Lett. 33: 1833-1834.

[18] Purnomo, M. F. E. Basari. And Sumantyo, J. T. S. 2014. Circularly Polarized Stack-Patch Microstrip Array Antenna for Mobile Satellite Communications. Proceedings IJJSS 2014. Theme Antenna and Microwave. 269-275. 